\title{
IMPLEMENTASI KADASTER LAUT DALAM RANCANGAN PERATURAN PEMERINTAH (RPP) DAN RANCANGAN PERATURAN MENTERI (RAPERMEN) TENTANG IZIN LOKASI PEMANFAATAN RUANG LAUT BERBASIS WEBGIS (STUDI KASUS: PULAU MARATUA, BERAU, KALIMANTAN TIMUR)
}

\author{
Yanto Budisusanto ${ }^{1}$ dan Aulia Rachmawati ${ }^{2}$ \\ ${ }^{1,2}$ Departemen Teknik Geomatika, FTSLK-ITS, Kampus ITS Sukolilo, Surabaya, 60111, Indonesia \\ e-mail: ${ }^{1}$ yanto_b@geodesy.its.ac.id
}

\begin{abstract}
Abstrak
Penerapan konsep kadaster kelautan diharapkan dapat menghasilkan data dan informasi yang lengkap, akurat, dan seragam sehingga data daninformasi dapat digunakan untuk saling berbagi pakai dan dirubah secara cepat (Syarif 2012). Adagium abad ketujuhbelas yang menyatakan ruang laut adalah kepunyaan bersama, tersedia untuk semua tetapi tidak untuk dimiliki. Negara mengatur penguasaannya kepada pihak lain (baik itu perseorangan atau swasta) dalam bentuk izin. Saat ini proses pendaftaran izin lokasi oleh KKP dilaksanakan secara offline. Penelitian ini akan merancang sebuah Website Sistem Informasi Geografis (SIG) pendaftaran izin lokasi pemanfaatan ruang laut. Lokasi penelitian berada pada Pulau Maratua, Kecamatan Maratua, Kabupaten Berau, Kalimantan Timur yaitu pada koordinat $2^{\circ} 04^{\prime} 11,38^{\prime \prime}-2^{\circ} 20^{\prime} 11,10^{\prime \prime} \mathrm{LU}$ dan $118^{\circ} 31^{\prime} 48,93^{\prime \prime}-118^{\circ} 45^{\prime} 29,56^{\prime \prime}$ BT. Data spasial yang digunakan adalah peta dasar kadaster laut, rencana zonasi dan eksisting pemanfaatan ruang laut. RPP dan RAPERMEN izin lokasi digunakan untuk membangun sistem pendaftaran berbasis WebGIS. Implementasi basis data menggunakan PostgreSQL 9.0 dan Google Maps API sebagai penampil peta. Website dapat diakses secara online pada http:// www.kadasterlautmaratua.com sehingga proses pendaftaran izin lokasi dapat dilaksanakan secara online. Dari hasil uji kebergunaan beerdasarkan 30 responden menunjukkan persentase $86.00 \%$. Berdasarkan hasil tersebut maka website termasuk kategori sangat layak sesuai dengan tabel Kategori Penilaian Usability dengan rentang nilai $81 \%-100 \%$.
\end{abstract}

Kata kunci : Kadaster Laut, Izin Lokasi, WebGIS, PostgreSQL. Google Maps API, Uji Kebergunaan

\begin{abstract}
Goal from Implementation of marine cadastre concept is to produce complete, accurate, and equal data and information, so that data and information can be used to share and change quickly (Sharif 2012). Seventeenth century adage that states sea space belongs to everyone, available for all, but not for own. The State regulates its control to other parties (whether private or private) in the form of a permit. Currently the location permit registration process by KKP in offline. This research will design a Geographic Information System (GIS) Website registration permit location of sea space utilization. The research are located on Maratua Island, Maratua District, Berau District, East Kalimantan at coordinates $2^{\circ} 04^{\prime} 11,38^{\prime \prime}-2^{\circ} 20^{\prime} 11,10^{\prime \prime} L U$ and $118^{\circ} 31^{\prime} 48,93$ "-118 $45^{\prime} 29.56$ "BT. Spatial data used in this research is sea cadastre basemap, zoning plan and existing sea space utilization. RPP and RAPERMEN location permits are used to build WebGIS-based enrollment systems. Implementation of database using PostgreSQL 9.0 and Google Maps API as map viewer. The website can be accessed online at http: // www.kadasterlautmaratua.com so the registration location permit process can be online. From the results of usability test based on 30 respondents get $86.00 \%$. Based on these results, the website is categorized as very feasible according to Category Usability Test table with a range of values 81\%-100\%.
\end{abstract}

Keywords : Marine Cadastre, Location Permit, WebGIS, PostgreSQL, Google Maps API. Usability Test 


\section{PENDAHULUAN}

Kadaster Kelautan di Indonesia merupakan kelanjutan dari penerapan prinsip-prinsip kadaster darat (Rais 2003). Prinsip-prinsip Kadaster yang diterapkan meliputi hak, batas dan tanggung jawab terhadap persil-persil ruang laut. Penerapan konsep kadaster kelautan diharapkan dapat menghasilkan data/ informasi yang lengkap, akurat, dan seragam sehingga data/informasi dapat digunakan untuk saling berbagi pakai dan dirubah secara cepat (Syarif 2012). Adagium abad ketujuhbelas yang menyatakan ruang laut adalah kepunyaan bersama, tersedia untuk semua tetapi tidak untuk dimiliki. Negara mengatur penguasaannya kepada pihak lain (baik itu perseorangan atau swasta) dalam bentuk izin. Setiap orang yang melakukan pemanfaatan ruang wilayah perairan pesisir dan sebagian pulau-pulau kecil secara menetap diwajibkan memiliki izin lokasi sesuai Rencana Zonasi Wilayah Pesisir Dan Pulau-Pulau Kecil (RZWP3K) (Pasal 17 UU RI No.1 tahun 2014).

Kementrian Kelautan dan Perikanan merancang regulasi tentang izin lokasi dalam bentuk Rancangan Peraturan Pemerintah (RPP) Izin Lokasi Perairan dan Izin Pengelolaan Perairan di Wilayah Pesisir dan Pulau-Pulau Kecil (WP3K) dan Rancangan Peraturan Menteri (RAPERMEN) Kelautan dan Perikanan tahun 2017 tentang Peraturan Pelaksanaan Peraturan Pemerintah tahun 2017 Tentang Izin Lokasi dan Izin Pengelolaan di Wilayah Pesisir dan PulauPulau Kecil (WP3K). Saat ini proses pendaftaran izin lokasi oleh KKP dilaksanakan secara offline.

Kemajuan teknologi dan perilaku masyarakat yang telah berganti ke digital mengharuskan semua sistem berganti ke sistem digital dan dapat diakses secara online sehingga dapat diakses oleh masyarkat luas. Penelitian ini akan merancang sebuah Website Sistem Informasi Geografis (SIG) pendaftaran izin lokasi pemanfaatan ruang laut. Sistem ini akan menampilkan data dan peta kadaster laut yang terdiri dari data peta dasar kadaster laut, rencana zonasi dan eksisting pemanfaatan ruang laut. Data tersebut telah terpenuhi pada wilayah Pulau Maratua, Berau, Kalimantan Timur. Oleh karena itu Pulau Maratua menjadi studi kasus dalam penelitian ini.
Adapun tujuan yang ingin dicapai dalam penelitian ini adalah menggantikan proses pendaftaran izin secara offline menjadi online. Perubahan sistem ini akan memudahkan pihak pemohon untuk mendapatkan informasi mengenai data izin lokasi dan data kadaster laut wilayah Pulau Maratua. Peta yang akan ditampilkan pada website dapat digunakan oleh pemohon untuk mendefinisikan wilayah yang akan diajukan dengan menggambar langsung pada peta dan menampalkannya dengan data peta yang tersedia. Proses penampalan tersebut bertujuan agar pemohon dapat mengetahui lokasi yang akan memiliki potensi masalah ketika diajukan izin lokasi. Data yang masuk akan tersimpan ke dalam sistem dan akan dilakukan verifikasi berkas oleh pihak KKP.

\section{METODE}

\section{Lokasi Penelitian}

Lokasi penelitian berada pada Pulau Maratua, Kecamatan Maratua, Kabupaten Berau, Kalimantan Timur yaitu pada koordinat $2^{\circ} 04^{\prime} 11,38^{\prime \prime}$ $2^{\circ} 20^{\prime} 11,10^{\prime \prime}$ LU dan $118^{\circ} 31^{\prime} 48,93^{\prime \prime}$ $118^{\circ} 45^{\prime} 29,56^{\prime \prime}$ BT.

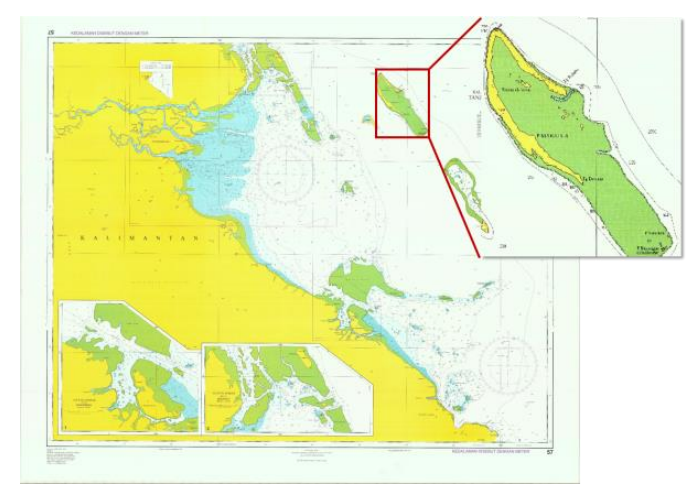

Gambar 1. Lokasi Penelitian (Sumber: Peta Laut Kalimantan Timur DISHIDROS-AL, 2013)

\section{Tahap Pengolahan Data}

Tahapan setelah convert data kemudian melakukan perancangan dan implementasi database pada PostgreSQL, membuat layer Google Maps, merancang sistem pendaftaran, merancang webGIS. Setelah website dirancang dan dapat tampil localhost kemudian dilakukan import script dan basis data ke hosting yang telah dibeli. Tahap terakhir pada penelitian yaitu analisa berdasarkan nilai uji kebergunaan website yang diberikan oleh responden. 


\section{HASIL DAN PEMBAHASAN}

\section{Implementasi Basis Data}

Implementasi basis data pada penelitian ini dilakukan di PostgreSQL dengan menggunakan software pengelola basis data PostgreSQL 9.0 adalah PgAdmin III. Hasil pembuatan tabel pada PgAdmin III terdiri dari 17 entitas. Entitas-entitas tersebut terdiri dari:

1. Peta_pendaftaran, entitas yang akan menyimpan informasi peta yang didaftarkan.

2. Lampiran, entitas yang akan menyimpan informasi lampiran identitas peta.

3. Lampiran, entitas yang akan menyimpan informasi lampiran kondisi lokasi.

4. Persil, entitas yang akan menyimpan informasi persil pemohon.

5. Koordinat, entitas yang akan menyimpan informasi koordinat yang dimiliki setiap persil.

6. Kondisi_lokasi, entitas yang akan menyimpan informasi lokasi yang didaftarkan.

7. Registrasi_izin, entitas yang yang akan menyimpan detail registrasi pemohonan izin.

8. Users, entitas yang akan menyimpan pengguna yang mendaftar ke sistem.

9. Role_user, entitas yang akan menyimpan role pengguna.

10. Roles, entitas yang mencatat data referensi role.

11. Password_resets, entitas yang akan menyimpan setiap perubahan password pengguna.

12. Maps, entitas yang akan menyimpan informasi peta Google Maps.

13. Pemanfaatan, entitas yang akan menyimpan informasi pemanfaatan ruang laut

14. Villages, entitas yang berisi informasi namanama kelurahan se-Indonesia.

15. Districts, entitas yang berisi informasi namanama kecamatan se-Indonesia.

16. Regencies, entitas yang berisi informasi nama-nama kotamadya / kabupaten seIndonesia.

17. Provincies, entitas yang berisi informasi nama-nama provinsi se-Indonesia.

\section{- Prosedur Pendaftaran pada Website}

RAPERMEN izin lokasi yang berisi peraturan pelaksanaan peraturan pemerintah tentang izin lokasi kemudian diterjemahkan kedalam alur pengajuan pendaftaran izin. Secara sederhana proses pengajuan hingga mendapat file persetujuan/penolakan adalah sebagai berikut:

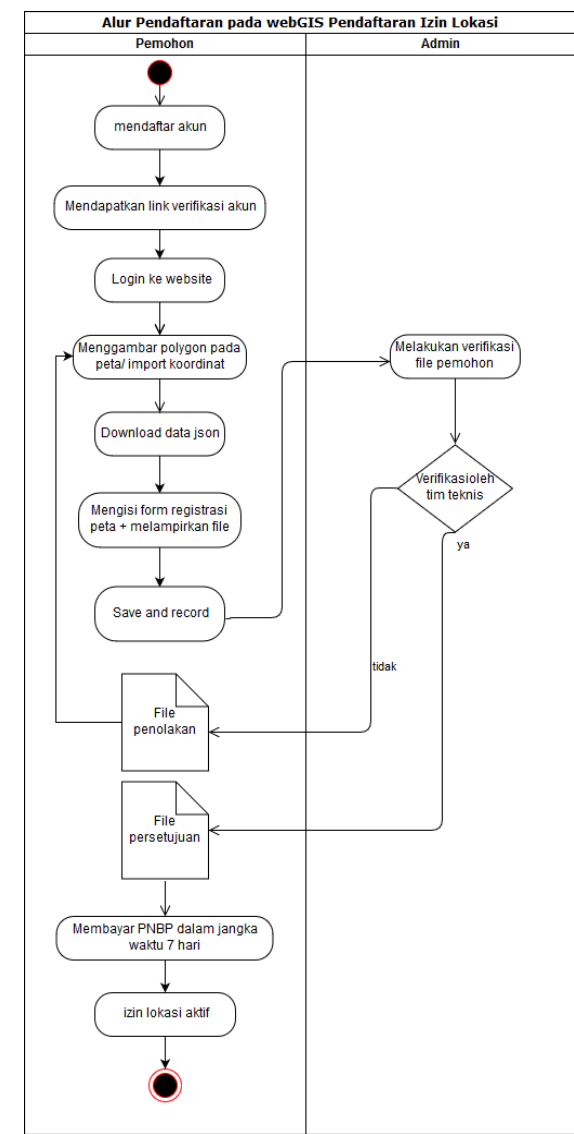

Gambar 2. Activity Diagram Prosedur Pengajuan Izin Lokasi

Keterangan:

1) Pemohon melakukan pendaftaran ke website dengan menginput data diri.

2) Admin mengirim link verifikasi ke email pemohon.

3) Pemohon melakukan login dari link verifikasi.

4) Pemohon menggambar polygon pada peta / input koordinat pada menu import koordinat

5) Pemohon mendownload data json

6) Pemohon melengkapi form dan mengunggah dokumen yang diperlukan untuk memenuhi persyaratan administrasi dan teknis.

7) Admin akan meneruskan kepada tim teknis semua dokumen pemohon untuk dilakukan penilaian dan verifikasi. 
8) Pemohon menerima dokumen persetujuan atau penolakan pendaftaran izin lokasi dengan waktu maksimal 30 hari kerja sejak pemohon mengajukan permohonan secara lengkap.

\section{Template Google Maps API}

Template Google Maps API yang menunjukkan Pulau Maratua sebagai center yaitu pada koordinat (2.2375078, 118.5371442). berikut adalah script Google Maps API yang telah dimodifikasi.

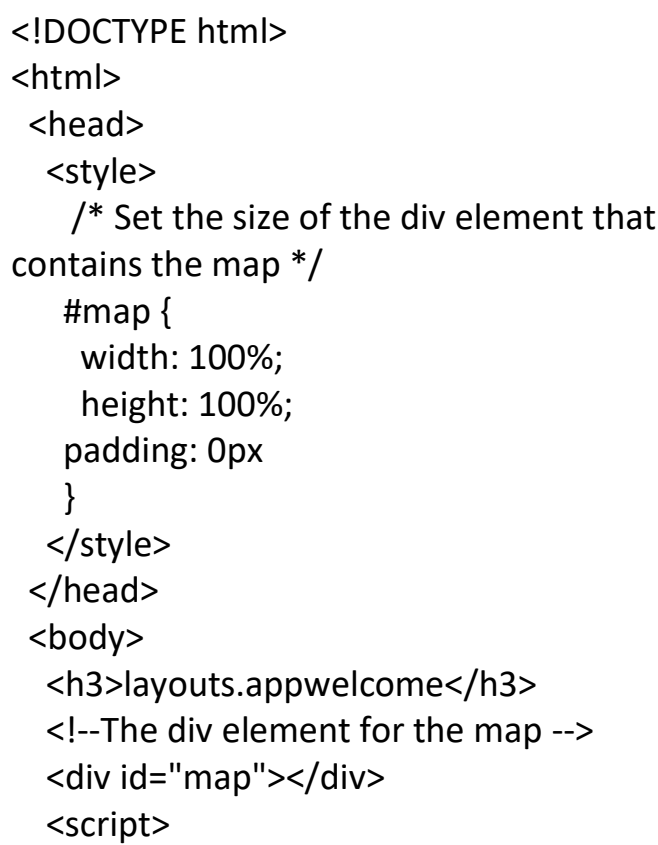

$</$ body $>$

$</$ html $>$

\section{Aplikasi dan UI website}

WebGIS dapat diakses secara online pada http://kadasterlautmaratua.com. Halaman yang ditampilkan adalah halaman Login, Home, Maps (berisi sub halaman My Maps, Maps Registrasi, Peta Dasar (.mpk) dan Import Koordinat), Info Registrasi, FAQ, Manual, Kuisioner, Administrator dan Sign Out. Website dapat diakses pada mobile karena website telah dirancang agar responsif terhadap platform yang digunakan oleh pengguna. Gambar Berikut adalah tampilan website pada komputer dan smartphone.

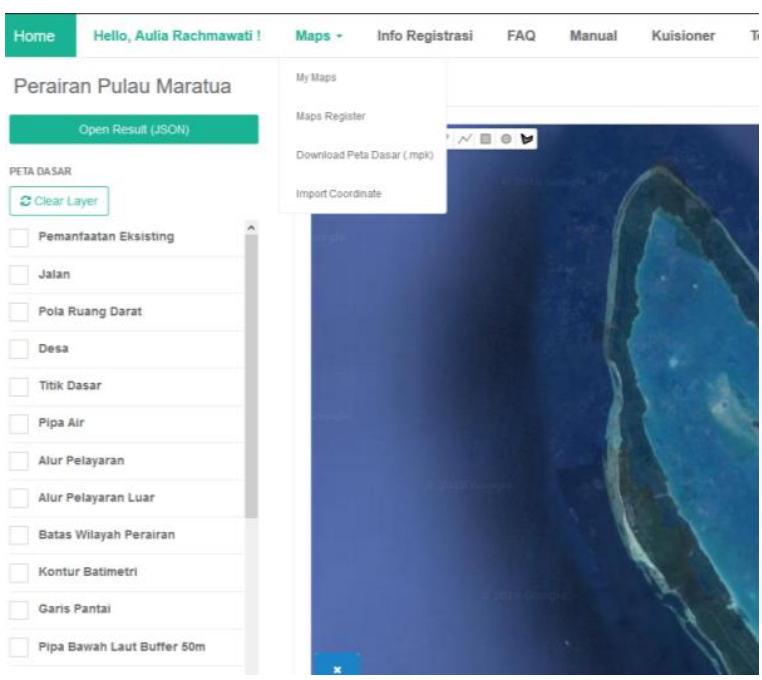

Gambar 3. Tampilan Halaman Pada Komputer

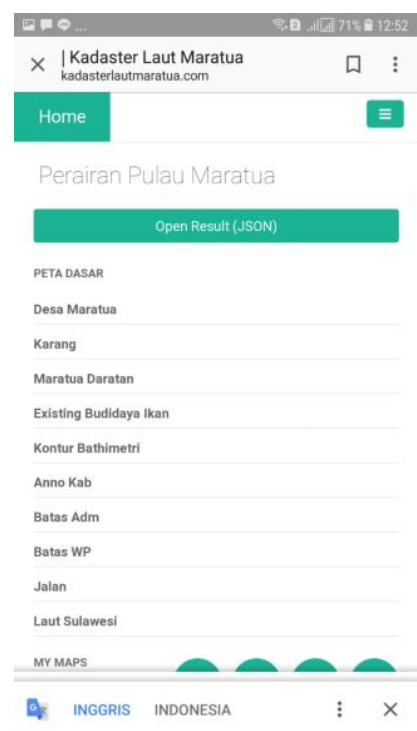

Gambar 4. Tampilan Halaman Pada Platform Android 


\section{Uji Kebergunaan}

Pertanyaan yang terdapat dalam kuisioner mewakili 5 aspek uji kebergunaan yaitu kemudahan untuk dipelajari, efisiensi, mudah diingat, kesalahan, dan kepuasan website. Detail pertanyaan uji kebergunaan pada website ini dapat dilihat di lampiran 4 pada laporan ini. Hasil uji kebergunaan diperoleh berdasarkan 30 orang responden/ pengguna semenjak WebGIS Pendaftaran Izin Lokasi (www.kadasterlautmara tua.com) dipublikasikan pada tanggal dari tanggal 8 Juli 2018. Responden yang mengunjungi halaman ini dengan jenis kelamin laki-laki sebanyak 14 orang, dan perempuan 16 orang yang berasal dari institusi perguruan tinggi 13 orang, pegawai dinas 2 orang dan hasil sisanya adalah masyarakat umum. Hasil persentase penilaian dari 30 pengguna yaitu sebesar 86.00 $\%$. Berdasarkan hasil tersebut maka website termasuk kategori sangat layak sesuai dengan tabel Kategori Penilaian Usability dengan rentang nilai $81 \%-100 \%$.

\section{KESIMPULAN}

Dari hasil pembuatan WebGIS Pendaftaran Izin Lokasi Pemanfaatan Ruang Laut Pulau Maratua dapat disimpulkan bahwa:
1. Pendaftaran izin lokasi dapat dilaksanakan secara online pada http://kadasterlautmaratua.com.

2. Pengguna dapat mengakses semua informasi mengenai izin lokasi baik berupa data spasial berupa peta Google Maps dan data non spasial berupa syarat dan prosedur pengajuan permohonan izin lokasi.

3. Pengguna dapat melakukan analisa awal terhadap lokasi yang akan diajukan izin lokasi dengan melakukan penampalan lokasi yang telah digambar dengan layerlayer peta yang telah tersedia.

\section{UCAPAN TERIMA KASIH}

Penulis mengucapkan terimakasih kepada Kementrian Kelautan dan Perikanan (KKP) yang telah bersedia memberikan bantuan data serta Kemenristekdikti yang telah memberi kesempatan kepada penulis untuk melakukan penelitian dan memberikan bantuan berupa dana melalui Program Kreatifitas Mahasiswa (PKM).

\section{DAFTAR PUSTAKA}

KKP RI, 2017, Rancangan Peraturan Pemerintah (RPP) Republik Indonesia Tahun 2017 Tentang Izin Lokasi dan Izin Pengelolaan Wilayah Pesisir dan PulauPulau Kecil Kementrian Kelautan dan Perikanan. Sekretariat KKP RI, Jakarta

KKP RI, 2017, Rancangan Peraturan Menteri (RAPERMEN) Kelautan dan Perikanan Tahun 2017 Tentang Peraturan Pelaksanaan Peraturan Pemerintah Tentang Izin Lokasi dan Izin Pengelolaan di Wilayah Pesisir dan Pulau-Pulau Kecil (WP3K). Sekretariat KKP RI, Jakarta.

Republik Indonesia, 2014, Undang-Undang No.1 Tahun 2014 Tentang Perubahan Atas Undang-Undang No.27 Tahun 2007 Tentang Pengelolaan Wilayah Pesisir dan Pulau-Pulau Kecil. Sekretariat Kabinet $\mathrm{R}$,. Jakarta

Rais, J, 2003, Pedoman Penentuan Batas Wilayah Laut Kewenangan Daerah Menurut UU No.22/1999 dalam Koleksi Dokumen Proyek Pesisir 19972003, Jakarta : USAID

Syarif, P. 2012. Kajian Aspek Hukum dan Teknis tentang Pendaftaran untuk Bangunan Atas Air. Tugas Akhir. Program Studi Sarjana Teknik Geodesi dan Geomatika, ITB. Bandung. 